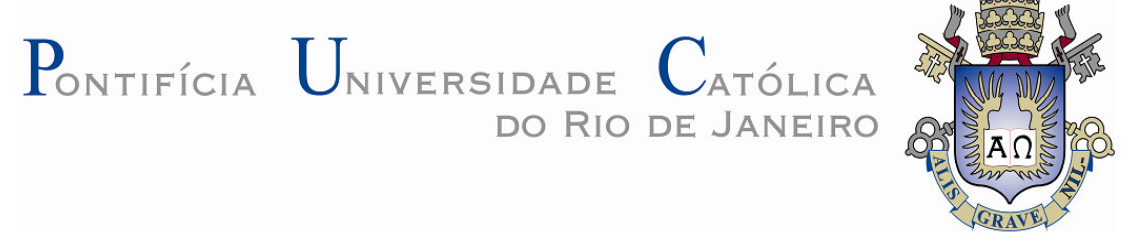

Perlita Rosmery Esaine Barrantes

\title{
Análise sísmica e hidromecânica de uma barragem de terra zonada no Peru
}

\section{Dissertação de Mestrado}

Dissertação apresentada como requisito parcial para obtenção do grau de Mestre pelo Programa de Pósgraduação em Engenharia Civil do Departamento de Engenharia Civil da PUC-Rio.

Orientador: Prof. Celso Romanel

Rio de Janeiro Abril de 2013 


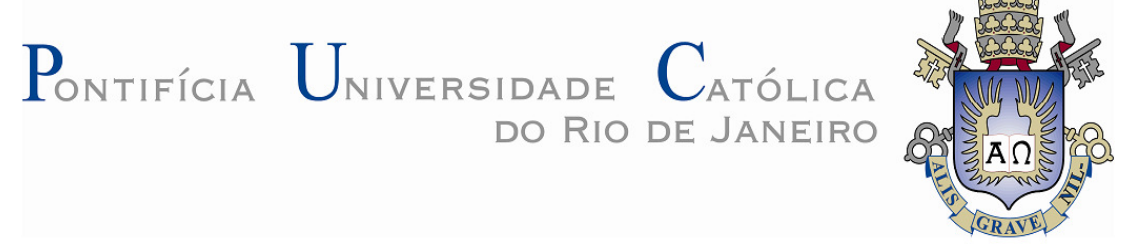

Perlita Rosmery Esaine Barrantes

\section{Análise sísmica e hidromecânica de uma barragem de terra zonada no Peru}

Dissertação apresentada como requisito parcial para obtenção do grau de Mestre pelo Programa de PósGraduação em Engenharia Civil do Departamento de Engenharia Civil do Centro Técnico Científico da PUCRio. Aprovada pela Commissão Examinadora abaixo assinada.

\section{Prof. Celso Romanel} Orientador Departamento de Engenharia Civil - PUC-Rio

Profa. Michéle Dal Toé Casagrande Departamento de Engenharia Civil - PUC-Rio

Prof. Celso Romanel Co-Orientador Departamento de Engenharia Civil - PUC-Rio

Profa. Ana Cristina Castro Fontenla Sieira Universidade do Estado do Rio de Janeiro

Prof. José Eugenio Leal Coordenador Setorial do Centro

Técnico Científico - PUC-Rio

Rio de Janeiro, 15 de Abril de 2013. 
Todos os direitos reservados. É proibida a reprodução total ou parcial do trabalho sem autorização da universidade, do autor e do orientador.

\section{Perlita Rosmery Esaine Barrantes}

Graduou-se em Engenharia Civil pela Universidade Nacional de Cajamarca - UNC (Cajamarca-Peru) em 2000. Principais áreas de interesse: geotecnia computacional e barragens.

Ficha Catalográfica

Barrantes, Perlita Rosmery Esaine

Análise Sísmica e Hidromecânica de uma Barragem de Terra Zonada no Peru / Perlita Rosmery Esaine Barrantes ; orientador: Celso Romanel - 2013.

191 f. il. (color.) ; $30 \mathrm{~cm}$

Dissertação (mestrado)-Pontifícia

Universidade Católica do Rio de Janeiro, Departamento de Engenharia Civil, 2013.

Inclui bibliografia

1. Engenharia civil - Teses. 2. Modelagem numérica. 3. Análise hidromecânica. 4. Análise dinâmica. 5. Hardening soil model. 6. Barragem de terra. I. Romanel, Celso. II. Pontifícia Universidade Católica do Rio de Janeiro. Departamento de Engenharia Civil. III. Título. 
Aos meus pais, Wilzet e Jenny,

Pelo amor, compreensão, apoio e incentivo. 


\section{Agradecimentos}

A Deus, meu pai... tenho certeza que me acompanhou durante todo este caminho, foi duro sim, mas também tive muitas alegrias e agradeço a Ele porque hoje ao encerrar esta etapa levo além dos conhecimentos aprendidos, uma experiência de vida que me fez crescer e ser mais forte.

Aos meus pais, Wilzet e Jenny e meus irmãos Fernando e Elizabeth, porque mesmo de longe me incentivaram para atingir este momento e tiveram que conviver com minha falta.

Ao professor Celso Romanel, pela valiosa e paciente orientação e conhecimentos transmitidos.

As pessoas que de alguma maneira influíram na realização deste trabalho, especialmente ao Gary Durán, pela sua paciente companhia e amizade, a Lidia Pacheco pelo seu carinho e alegria em todo momento, ao Frank Pérez que soube compartilhar e transmitir seus conhecimentos para enriquecer este trabalho, a Mariana Benessiuti pela sua amizade e conselhos, a Miriam Escayala e Ronald Macazana que me ofereceram apoio incondicional desde o início do mestrado.

Aos meus amigos e colegas da PUC-Rio que conviveram e compartilharam comigo todo este tempo e se converteram em minha família brasileira, dos quais não vou mencionar nomes para não esquecer ninguém.

A Merit, a empresa que me deu apoio e incentivo para dar este último passo, através do Nick Blanchette, agregando mais valor a esta meta. 
A todos os professores e funcionários do Departamento de Engenharia Civil da PUC-Rio.

A CAPES pelo apoio financeiro.

Ao Brasil e seu povo acolhedor, obrigada pela oportunidade... 


\section{Resumo}

Barrantes, Perlita Rosmery Esaine; Romanel, Celso (orientador) Análise sísmica e hidromecânica de uma barragem de terra zonada no Peru. Rio de Janeiro, 2013. 191 p. Dissertação de Mestrado - Departamento de Engenharia Civil, Pontifícia Universidade Católica do Rio de Janeiro.

Prever o comportamento de estruturas de solo de grande porte, como barragens, durante a construção, em operação e inclusive sob o efeito de eventos sísmicos tem muita importância para evitar possíveis consequências catastróficas e indesejáveis. Neste sentido, este estudo apresenta, através de uma análise acoplada hidromecânica pelo método dos elementos finitos, os resultados numéricos discutidos em termos de tensões e suas trajetórias, deslocamentos verticais e horizontais, poropressões, incluindo a estabilidade de taludes. Além disso, é apresentada também a análise da resposta sísmica quando a estrutura é submetida a um carregamento dinâmico. Para tanto, analisou-se a barragem de terra zonada Recreta, situada na província de Huaraz - Peru, mediante o emprego do programa PLAXIS 2010. Foram descritas as metodologias de análise para simular passo a passo a construção incremental da barragem, o primeiro enchimento do reservatório por incrementos de níveis de água, o avanço da frente de saturação até atingir a condição de fluxo permanente e a avaliação da resposta dinâmica quando a barragem é submetida ao último maior movimento sísmico (história de acelerações) registrado em 1974 na capital do Peru, Lima, adjacente à cidade onde se localiza este projeto. Também se empregou o software Seismosignal versão 5.0, para o tratamento do sinal sísmico, e os programas Shake 2000 e Strata para a calibração dos parâmetros de amortecimento. Os resultados fornecidos por estas ferramentas numéricas foram avaliados em função do fundamento teórico, exposto na revisão bibliográfica, e de uma série de testes para o estabelecimento das metodologias e procedimentos mais adequados para a obtenção destes resultados.

\section{Palavras - chave}

Modelagem numérica; análise hidromecânica, análise dinâmica, Hardening soil model, barragem de terra. 


\section{Abstract}

Barrantes, Perlita Rosmery Esaine; Romanel, Celso (advisor). Seismic and hydromechanical analysis of a zoned earth dam in Peru. Rio de Janeiro, 2013. 191 p. M.Sc. Dissertation - Departamento de Engenharia Civil, Pontifícia Universidade Católica do Rio de Janeiro.

Predicting the behavior of soil structures, such as large-scale dams, during construction and operation, including the effect of earthquakes, is very important to prevent possible catastrophic and undesirable consequences. This study presents, through a coupled hydromechanical analysis by the finite element method, numerical results discussed in terms of stresses and trajectories, vertical and horizontal displacements, poropresssures and soil slope stability analyses. The investigation of the seismic response when the structure is subjected to a seismic load is also included, considering the dynamic behavior of the zoned earth dam Recreta, located in the province of Huaraz in Peru. The numerical analyses were carried out using the computational program PLAXIS 2010 to simulate the incremental construction of the dam, the first fill of the reservoir by increments of the water levels, the advance of the front of saturation until achieving the condition of steady flow condition and the seismic response when the dam is subject to the last major earthquake (accelerations history) registered in Peru's capital, Lima, in 1974, which is located near to the site of the Recreta dam. The Seismosignal software version 5.0 was also used for seismic signal processing and the programs SHAKE 2000 and STRATA were also employed for calibration of the damping parameters of the soils. All the results provided herein were discussed, based on the theoretical basics presented in the literature review as well as on the various numerical examples investigated with the main purpose to better understand the hydromechanical behavior of a zoned earth dam subject to static and dynamic loads.

\section{Keywords}

Numerical modeling, hydromechanical analysis, dynamic analysis, Hardening soil model, earth dam. 


\section{Sumário}

1 Introdução

2 Comportamento estático e dinâmico de barragens de terra 27

2.1. Introdução 27

2.2. Comportamento durante a fase de construção da barragem 27

2.2.1. Distribuição dos recalques $\quad 27$

2.2.2. Influencia da anisotropia 30

2.3. Comportamento durante o enchimento do reservatório 31

2.3.1. Percolação por fundações e barragens 31

2.3.2. Comportamento durante o primeiro enchimento 34

2.3.3. Pressão hidráulica no núcleo 35

2.3.4. Pressão hidráulica na fundação e sub pressão no núcleo central 36

2.3.5. Sub pressão a montante 36

2.3.6. Colapso devido à saturação 37

2.4. Transferência de cargas $\quad 37$

2.4.1. Transferência de cargas do aterro para as ombreiras 37

2.4.2. Transferência de cargas entre o núcleo e os espaldares

2.5. Trajetória de tensões 39

2.5.1. Trajetória de tensões durante a construção 39

2.5.2. Trajetória de tensões durante o enchimento 40

2.6. Análise de estabilidade e segurança de barragens 42

2.6.1. Estabilidade durante a construção 45

2.6.2. Estabilidade em condição de fluxo permanente com reservatório cheio 46

2.6.3. Estabilidade durante o rebaixamento rápido 46

2.6.4. Segurança do fluxo em barragens 47

2.6.5. Erosão regressiva 49

2.7. Conceitos de sismologia 49 
2.7.1. Estrutura interna da terra 50

2.7.2. Ondas sísmicas 50

2.7.3. Grandeza de um sismo 54

2.7.4. Parâmetros do movimento do terreno 56

2.7.5. Quantificação do movimento do terreno 60

2.7.6. Frequência fundamental do sistema 61

2.8. Fatores que influenciam a resposta sísmica 61

2.8.1. Efeitos da fundação 62

2.8.2. Efeitos da não linearidade dos materiais 64

2.8.3. Não homogeneidade da barragem 65

2.9. Características da resposta sísmica 66

2.9.1. Excitação dos modos de vibração 66

2.9.2. Amplificação na crista 67

2.9.3. Degradação da rigidez dos materiais 68

2.10. Comportamento tensão-deformação sob carregamentos cíclicos 69

2.10.1. Amplificação dinâmica de solos 69

2.10.2. Parâmetros de amplificação 70

2.10.3. Módulo de cisalhamento máximo $\mathrm{G}_{\operatorname{máx}} \quad 72$

2.10.4. Curva de redução do módulo cisalhante $\mathrm{G} / \mathrm{G}_{\max }$

2.10.5. Razão de amortecimento 76

2.10.6. Critério do módulo de descarregamentorecarregamento

3 Modelos constitutivos $\quad 80$

3.1. Introdução 80

3.2. Modelos constitutivos elasto-plásticos 80

3.2.1. Modelo de Mohr-Coulomb 80

3.2.2. Modelo hardening soil model - HSM 81

$\begin{array}{ll}\text { 3.2.3. Modelo linear equivalente } & 90\end{array}$

4 Modelagem numérica 93

4.1. Modelagem da fase de construção por camadas 93

4.1.1. Número de camadas 93 
4.2. Modelagem da fase do primeiro enchimento 94

4.2.1. Número de etapas de enchimento 94

4.3. Modelagem da fase dinâmica 95

4.3.1. Transmissão de ondas 95

4.3.2. Filtragem do registro sísmico 96

4.3.3. Correção da linha base 97

4.3.4. Carregamento dinâmico 98

4.3.5. Condições de contorno 99

4.3.6. Amortecimento mecânico 100

4.3.7. Efeitos da geometria do modelo de elementos finitos 105

5 Análise da barragem Recreta 106

5.1. Análise estática da barragem Recreta 108

5.1.1. Características gerais 108

5.1.2. Parâmetros geotécnicos dos materiais 110

5.1.3. Condições de contorno 114

5.2. Resultados da análise estática 116

5.2.1. Apresentação dos resultados - fase de construção 117

5.2.2. Apresentação dos resultados do enchimento (fluxo $\begin{array}{ll}\text { transiente) e fluxo permanente } & 126\end{array}$

5.2.3. Apresentação dos resultados do rebaixamento rápido 143

5.2.4. Trajetórias de tensões efetivas 146

5.3. Análise de estabilidade 150

5.3.1. Análise de estabilidade durante a construção 150

5.3.2. Análise de estabilidade durante o enchimento e fluxo permanente

5.3.3. Análise de estabilidade em rebaixamento rápido 153

5.4. Análise dinâmica da barragem Recreta 154

5.4.1. Características gerais 154

5.4.2. Calibração do módulo de amortecimento do modelo 158

5.4.3. Tratamento do registro sísmico 165

5.4.4. Condições de contorno e carregamento dinâmico 168

5.5. Simulação da análise dinâmica 170 
5.6. Resultados da análise dinâmica 171

5.6.1. Tensão e deformação cisalhante máxima 172

5.6.2. Deslocamentos horizontais e verticais 172

5.6.3. Resposta história tempo acelerações 173

6 Conclusões 179

6.1. Analise estática 179

6.2. Analise dinâmica 181

6.3. Sugestões para pesquisas futuras 182

$\begin{array}{ll}\text { Referências bibliográficas } & 183\end{array}$

$\begin{array}{lr}\text { ANEXO } & 189\end{array}$ 


\section{Lista de Figuras}

Figura 2.1 - Construção de aterro de grande extensão por camadas sucessivas-Law, 1975

Figura 2.2 - Perfil de recalque em um aterro, com valor máximo a média altura $\mathrm{H} / 2$ (Law, 1975).

Figura 2.3 - Curvas de distribuição do recalque em diferentes etapas da construção do aterro (Law, 1975)

Figura 2.4 - Efeitos do primeiro enchimento do reservatório em uma barragem zonada (de Nobari e Duncan, 1972)

Figura 2.5 - Trajetórias de tensão durante a fase de construção (Naylor 1992)

Figura 2.6 - Trajetórias de tensão típicas no material de enrocamento (Veiga Pinto, 1983)

Figura 2.7 - Trajetórias de tensão típicas no material do núcleo central

(Veiga Pinto, 1983)

Figura 2.8 - Deformações produzidas por ondas de corpo: (a) ondas P e (b) ondas SV (Kramer, 1996).

Figura 2.9 - Ondas superficiais Love e Rayleigh (http://www.geologia.ufpr.br/graduacao/geofisica2007/ondassismi cas-aula1.pdf)

Figura 2.10 - Deformações causadas por ondas superficiais: (a) ondas de Rayleigh; (b) ondas de Love (Kramer, 1996).

Figura 2.11 - Ondas sísmicas registradas a 10.000km do epicentro: a) sismo de foco profundo; b) sismo de foco superficial (Sauter, 1989)

Figura 2.12- Acelerograma e suas principais características.

Figura 2.13 - Aceleração, velocidade e deslocamento tempo história do Giroy (Kramer, 1996)

Figura 2.14 - Espectro de amplitude de Fourier para o registro sísmico Giroy 2 (Kramer 1996). 
Figura 2.15 - Influência da frequência na resposta de uma camada linear, elástica amortecida (Kramer, 1996)

Figura 2.16 - Barragem e fundação em vale retangular (Dakoulas, 1990 apud Parra, 1996)

Figura 2.17 - Resposta não linear e linear na seção central de uma barragem sobre camada de fundação submetida a excitações harmônicas de $0,05 \mathrm{~g}$ e $0,20 \mathrm{~g}$. H1=espessura da fundação; $\mathrm{H} 2=$ altura da barragem; $\mathrm{V}_{\mathrm{S} 2}=\mathrm{V}_{\mathrm{S} 1}=$ velocidades de onda $\mathrm{S}$ na barragem e no solo de fundação, igual a $400 \mathrm{~m} / \mathrm{s}$; L=comprimento da barragem; $z$ = profundidade medida a partir da crista (Dakoulas, 1990).

Figura 2.18 - Espectro de amplificação da aceleração na barragem de Santa Felicia durante o terremoto de southern California 1976: (a) direção montante-jusante, b) direção paralela ao eixo da barragem (de Abdel-Ghaffar e Scott, 1979)

Figura 2.19 - Efeitos da amplificação em massas de rocha e solo...

Figura 2.20 - Efeito da amplificação em diferentes tipos de solo (de Seed et al, 1976).

Figura 2.21 - Gráfico tensão-deformação a) para um ciclo; b) histerético

Figura 2.22 - Esqueleto da curva mostrando a variação típica de $G_{\text {sec }}$ com a deformação cisalhante (Kramer, 1996)

Figura 2.23 - Variação do módulo de cisalhamento $K_{2 \max }$ para areias em densidades relativas em função das deformações cisalhantes - Seed e Idriss (1970).

Figura 2.24 - Faixa de variação de $\mathrm{G} / \mathrm{G}_{\max }$ com a deformação cisalhante para areias (Seed e Idriss, 1970).

Figura 2.25 - Faixa de variação de G/Gmax com a deformação cisalhante para pedregulhos (Seed e Idriss, 1970).

Figura 2.26 - Efeito do índice de plasticidade na curva de redução do módulo de cisalhamento de solos coesivos (Vucetic e Dobry,1991). 
Figura 2.27 - Variação da razão de amortecimento para areias (Seed e Idriss, 1970).

Figura 2.28 - Comparação da variação da razão de amortecimento para solos com pedregulho e areias (Seed et al., 1986).

Figura 2.29 - Efeito do índice de plasticidade nas curvas de variação da razão de amortecimento vs deformação cisalhante para solos coesivos (Vucetic e Dobry, 1991)

Figura 2.30 - Carregamento inicial e repetido (de Byrne et al., 1986) ......79

Figura 3.1- Critério de escoamento de Mohr-Coulomb: a) no plano ( $\sigma, \tau)$; b) em plano octaédrico (Ibañez, 2003).

Figura 3.2 - Idealização da relação tensão-deformação do modelo de elasto-plasticidade perfeita.

Figura 3.3 Superfície de fluência no espaço das tensões principais.

(Nieto, 2009) 82

Figura 3.4 - Módulo $E_{\text {oed }}^{\text {ref }}$ obtido a partir do ensaio odométrico (PLAXIS, 2010)

Figura 3.5 - Relação tensão-deformação hiperbólica para ensaios triaxiais consolidados drenados (PLAXIS, 2010) 85

Figura 3.6 - Modelo HSM. Superfícies de escoamento para vários valores de $\square^{p}$. (Ibañez, 2003)

Figura 3.7 - Modelo HSM. Superfície "cap" no plano p'-q. (Ibañez, 2003)

Figura 3.8 - Modelo HSM. Curva de deformação volumétrica para ensaio triaxial drenado com indicação de cut-off. (PLAXIS, 2010)....90

Figura 3.9 - Comportamento cíclico típico dos solos (Kramer, 1996): a) Relação tensão - deformação cisalhante para o primeiro ciclo de carregamento. b) Variação da rigidez em função do nível de deformação por cisalhamento.

Figura 4.1 : Influência do número de níveis d'água e incrementos de carga nos deslocamentos verticais durante 0 enchimento do reservatório (de Veiga Pinto, 1983)

Figura 4.2- Processo de correção da linha base (manual do FLAC v.5). 
Figura 4.3 - Influência dos parâmetros de amortecimento de Rayleigh.

(PLAXIS, 2010)

Figura 4.4-Variação da razão de amortecimento critico normalizada em relação à frequência angular. (Itasca, 2005 apud Bustamante, 2010)

Figura 4.5 - Elementos da barragem: altura $\mathrm{H}$, largura lateral da fundação B e largura da base da fundação W. Jiryaei (2010).

Figura 5.1 - Localização projetada da barragem de Recreta. (Parra, 1996)

Figura 5.2 - Características da fundação da barragem Recreta (Parra, 1996)

Figura 5.3 - Seção transversal A-A analisada (Parra, 1996) 108

Figura 5.4 - Seção transversal A-A, Perfis 1-1, 2-2, 3-3, 4-4 e camadas indicando os materiais e condições de contorno para análise estática (PLAXIS)

Figura 5.5 - Malha de elementos finitos para análise estática da barragem Recreta

Figura 5.6 - Modelo estendido para comprovar a influência da locação dos contornos.

Figura 5.7 - Influência dos contornos na leitura das a)Tensões principais e b) Deslocamentos verticais.

Figura 5.8 - Condições de contorno para o análise de fluxo

Figura 5.9 - Distribuição da rigidez após a construção e perfis 2-2 ($10 \mathrm{~m}$ do eixo) e 3-3 (-24m do eixo)

Figura 5.10 - Distribuição da tensão principal maior efetiva após construção e detalhe da seção 1-1.

Figura 5.11 - Distribuição da tensão principal menor efetiva após construção.

Figura 5.12 - Distribuição dos deslocamentos a) verticais e b) horizontais, caso 1.

Figura 5.13 - Distribuição dos deslocamentos a) verticais e b) horizontais. Após a décima primeira camada, caso 2. 
Figura 5.14 - Barragem homogênea para validação do cálculo dos deslocamentos verticais

Figura 5.15 - Validação do perfil de recalque calculado a partir do programa PLAXIS com os modelos Mohr Coulomb, HSM e a solução analítica, no eixo da barragem.

Figura 5.16 - Comparação dos deslocamentos verticais do caso 1: construção em uma etapa com o caso 2: construção incremental. Perfil 1-1 (eixo da barragem).

Figura 5.17 - Comparação dos deslocamentos horizontais Caso 1: construção em uma etapa com o Caso 2: construção incremental. Perfil 1-1 (eixo da barragem).

Figura 5.18 - Distribuição da rigidez após enchimento - perfil 3-3 ($24 \mathrm{~m}$ do eixo)

Figura 5.19 - Distribuição da tensão principal maior efetiva após enchimento.

Figura 5.20 - Distribuição da tensão principal maior efetiva após enchimento em fluxo permanente.

Figura 5.21- Distribuição da tensão efetiva principal menor após enchimento

Figura 5.22 - Zonas de plastificação após enchimento

Figura 5.23 - Superfície piezométrica após a fase 9 do primeiro enchimento incremental - caso 4.

Figura 5.24 - Posição da superfície freática em condição de fluxo permanente - Caso 5 .

Figura 5.25 - Deslocamentos verticais após a) fase 5 e b) fase 9 do enchimento incremental, caso 4.

Figura 5.26 - Deslocamento horizontal após a) fase 5 e b) fase 9 do enchimento incremental, caso 4 .

Figura 5.27 - Sentido dos deslocamentos totais após enchimento incremental, caso 4

Figura 5.28 - Deslocamentos verticais sem incluir os da construção, no eixo (Perfil 1-1). 
Figura 5.29 - Deslocamentos verticais sem incluir os da construção, à montante (Perfil 2-2) .......................................................... 136

Figura 5.30 - Deslocamentos horizontais sem incluir a construção, no eixo (Perfil 1-1)

Figura 5.31 - Deslocamentos horizontais sem incluir a construção, à montante (Perfil 2-2)

Figura 5.32 - Deslocamentos verticais do primeiro enchimento incluindo a construção, no eixo (Perfil 1-1)

Figura 5.33 - Deslocamentos verticais do primeiro enchimento incluindo a construção, à montante (Perfil 2-2) .

Figura 5.34 - Deslocamentos horizontais do primeiro enchimento incluindo os da construção, no eixo da barragem (perfil 1-1)

Figura 5.35 - Deslocamentos horizontais do primeiro enchimento incluindo os da construção, à montante (seção 2-2)

Figura 5.36 - Distribuição das poropressões após a fase 9 do primeiro enchimento, caso 4.

Figura 5.37 - Pressões de água no Perfil 1-1 (eixo da barragem) após enchimento.

Figura 5.38 - Pressões de água no Perfil 2-2 (montante) após enchimento

Figura 5.39 - Determinação do tempo para atingir o estado permanente.

Figura 5.40 - Distribuição da rigidez após o rebaixamento rápido e perfil 3-3 (-24m do eixo)

Figura 5.41 - Distribuição da tensão principal maior efetiva após rebaixamento rápido

Figura 5.42 - Distribuição da tensão efetiva principal menor após rebaixamento rápido

Figura 5.43 - Distribuição da resistência ao cisalhamento após rebaixamento rápido

Figura 5.44 - Distribuição da relação entre a tensão cisalhante mobilizada e a resistência ao cisalhamento máxima após rebaixamento rápido 
Figura 5.45- Distribuição do grau de saturação após rebaixamento ...... 146

Figura 5.46 - Pontos de controle de tensões efetivas ......................... 146

Figura 5.47 Trajetórias de tensões efetivas no núcleo na construção, enchimento e rebaixamento rápido.

Figura 5.48 - Trajetórias de tensões efetivas à montante na construção e enchimento

Figura 5.49 - Trajetória de tensões efetivas à jusante, na construção e enchimento.

Figura 5.50 - Superfície aproximada de rotura - após a) camada 5 e

b) camada 11 , caso 2 .

Figura 5.51 - Superfície aproximada de ruptura - fase de enchimento 9152

Figura 5.52 - Superfície aproximada de ruptura - condição permanente.

Figura 5.53- Superfície aproximada de ruptura - rebaixamento rápido em 5 dias.

Figura 5.54 - Secção transversal A-A

Figura 5.55 - Malha de elementos finitos para análise dinâmica da barragem Recreta - PLAXIS.

Figura 5.56 - Mapa de isoacelerações espectrais para 10\% de excedência em 100 anos (Alva e Castillo, 1993)

Figura 5.57- Curvas de isoacelerações para $10 \%$ de excedência em 100 anos na zona em estudo (Alva e Castillo, 1993), Peru.

Figura 5.58 - Seção transversal do modelo para calibração e pontos de controle

Figura 5.59- Determinação das razões de amortecimento ( $\square$ ) no programa Strata.

Figura 5.60-Frequencias fundamentais do modelo elástico (camadas horizontais)

Figura 5.61 - Calibração do PLAXIS com SHAKE 2000, para a) frequências 2,11 e 7,84 e $\xi=5 \%$ e $11 \%$, b) frequência 7,84 e $\xi$ $=4 \%$ e c) frequência 7,84 e $\xi=5 \%$

Figura 5.62- Registro de acelerações do terremoto de Lima de 03/10/1974 
Figura 5.63 - Registro normalizado das acelerações do terremoto de Lima de 03/10/1974 em relação à aceleração máxima de 0,26g no embasamento rochoso.

Figura 5.64 - Espectro de potência do registro de acelerações a) original e b) com filtro de $14,69 \mathrm{~Hz}$. (SeismoSignal)

Figura 5.65- História de velocidades com e sem correção da linha base (SeismoSignal) .....

Figura 5.66- História de deslocamentos com e sem correção da linha base (SeismoSignal)

Figura 5.67- História de aceleração horizontal na fase intensa do sismo considerando filtro de $14,69 \mathrm{~Hz}$ e corrigido por linha base. ... 168

Figura 5.68 - Carregamento dinâmico como história de tensões 169

Figura 5.69 - Locação dos pontos de controle. 170

Figura 5.70 - Espectro de potência das acelerações horizontais nãoamortecidas após construção. Frequências fundamentais $=1,84$ e $2,11 \mathrm{~Hz}$.

Figura 5.71-Distribuição de $\sigma 1^{\prime}$ após construção durante. 171

Figura 5.72-Deformaçao cisalhante máxima 172

Figura 5.73-Distribuição das tensões cisalhantes máximas ao final da excitação sísmica após construção.

Figura 5.74-Distribuição dos deslocamentos horizontais ao final da excitação sísmica após construção.

Figura 5.75-Deslocamentos horizontais obtidos durante a excitação sísmica após a construção

Figura 5.76-Comparação entre o tempo-história das acelerações de entrada e da resposta na a) cresta, topo da fundação b) da jusante e c) de montante da barragem após a construção. 176

Figura 5.77 - Espectro de resposta na a) cresta, b) na base da jusante e c) montante da barragem após a construção 


\section{Lista de Tabelas}

Tabela 2.1 - Valores típicos do coeficiente de permeabilidade $\mathrm{k}$ (Romanel, 2010)

Tabela 2.2 - Classificação quanto ao grau de permeabilidade

(Terzaghi e Peck, 1967)

Tabela 2.3-Levantamento de acidentes em barragens (Middlebrooks,

1953 apud Sandroni, 2012)

Tabela 2.4-Escala de Mercalli Modificada de intensidade sísmica

(http://pt.wikipedia.org/wiki/Escala_de_Mercalli) ..............................55

Tabela 2.5 - Escala de Ritcher de magnitude sísmica ..............................56

Tabela 2.6 - Estimativa de $K_{2, \max }$ (Seed e Idriss, 1970)...........................74

Tabela 3.1 - Parâmetros do modelo HSM (PLAXIS, 2010) …………........86

Tabela 4.1- Valores de c1 e c2 em função do coeficiente de Poisson v

(White et al, 1977 apud Bustamante, 2010) ................................... 100

Tabela 4.2- Valores típicos da razão de amortecimento crítico (Richart et al., 1970, apud Bustamante, 2010)......................................... 103

Tabela 5.1- Parâmetros do modelo hiperbólico para análise estática do comportamento da barragem e da fundação ............................112

Tabela 5.2- Parâmetros do modelo HSM para análise estática do comportamento da barragem e fundação .......................................113

Tabela 5.3 - Parâmetros de fluxo ..................................................... 114

Tabela 5.4 - Deslocamentos máximos e mínimos casos 1 e 2............... 121

Tabela 5.5 - Permeabilidade dos materiais da barragem ....................... 128

Tabela 5.6 Fatores de segurança por etapas de construção ................... 152

Tabela 5.7 Fatores de segurança durante o fluxo .................................. 153

Tabela 5.8 - Parâmetros do modelo Mohr Coulomb para análise dinâmica do comportamento da barragem e fundação .................... 156

Tabela 5.9 Valores representativos de critérios de projeto considerando movimentos sísmicos (Parra, 1996) 
Tabela 5.10- Fatores de redução do módulo cisalhante e razão de amortecimento em função da deformação cisalhante efetiva para os solo da barragem de Recreta (Parra, 1996) 161

Tabela 5.11- Cálculo dos coeficientes de amortecimento de Rayleigh .. 171 


\section{Lista de Símbolos}

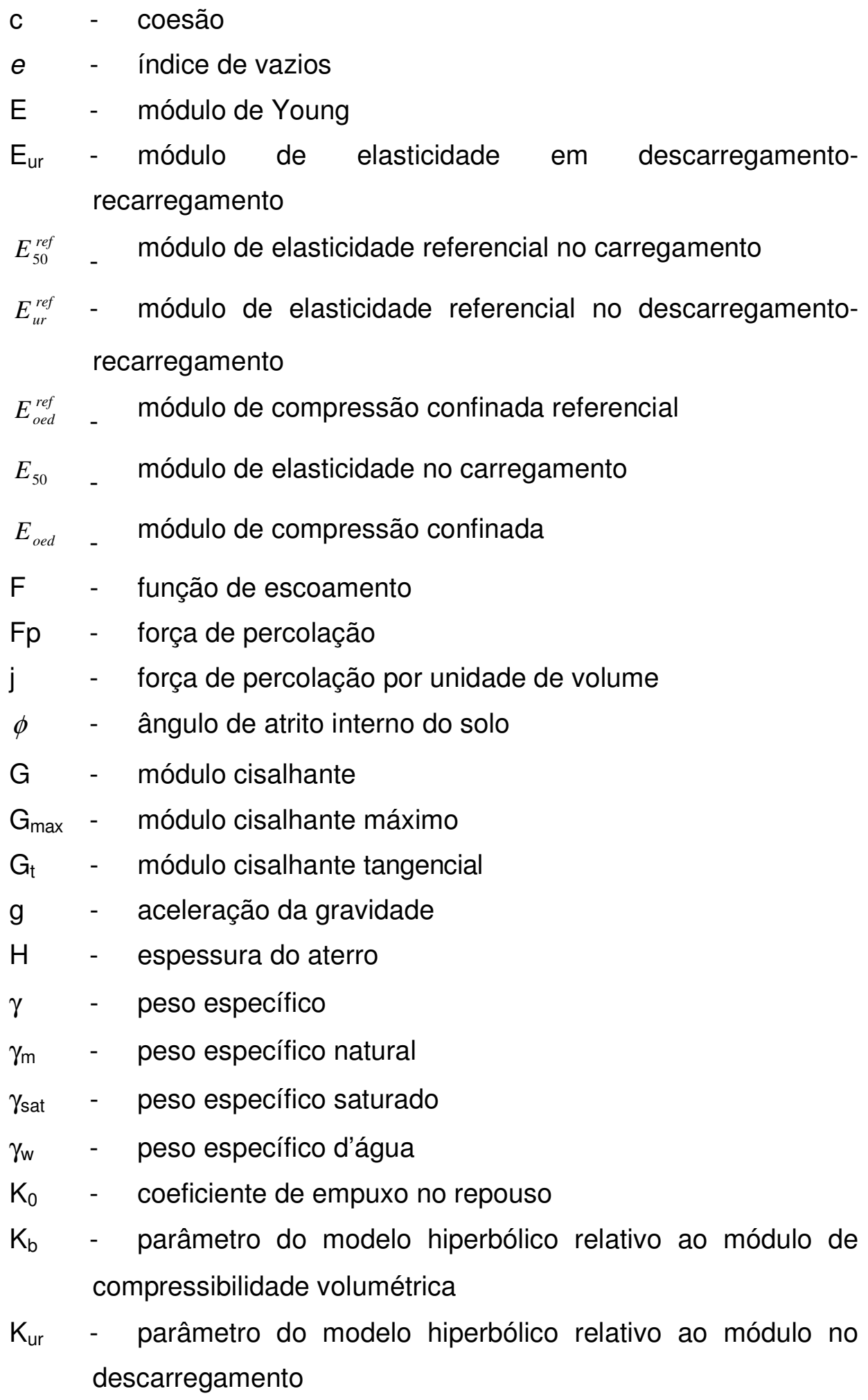




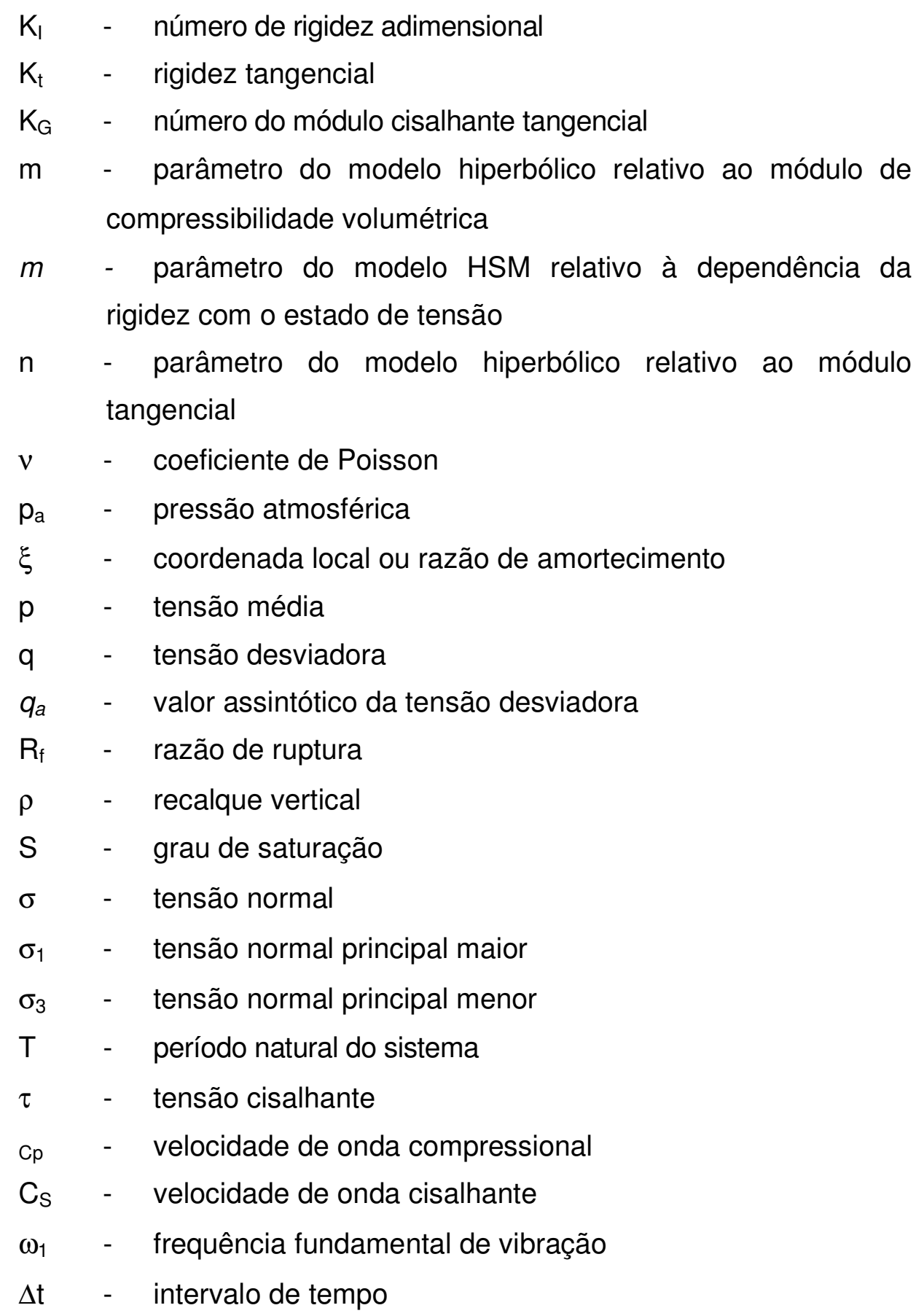

